\title{
Variation in the adductor muscle-scar rosette of Darwinula cicatricosa Wakefield, 1994 (Ostracoda, Crustacea), and comparison with other species of Darwinula
}

\author{
MATTHEW I. WAKEFIELD \\ British Gas PLC, Research \& Technology Division, Gas Research Centre, Ashby Road, Loughborough LE11 3 QU, UK.
}

\begin{abstract}
Variation in the morphology of the adductor muscle-scar pattern of Darwinula cicatricosa Wakefield, 1994 is demonstrated, and is shown to affect specific segments within the essentially tosette-shaped scar. Potential subdivisions of individual segments can be identified in fossil specimens as 'scar-sutures'. All fossil and Recent species of Darwinula studied are shown to have different patterns to their adductor muscle-scar rosette. These differences can be used as an aid in species identification. particularly of fossil species, in which the muscle-scars are the best indicator of soft part morphology. J. Micropalaeontol. 15(2): 151-160, October 1996.
\end{abstract}

\section{INTRODUCTION}

The aim of this paper is to demonstrate and explain the variation in the adductor muscle-scar (AMS) rosette of Darwinula cicatricosa Wakefield, 1994 from the Great Estuarine Group (Bathonian, Middle Jurassic) of the Inner Hebrides off NW Scotland (Figs 1 \& 2). The results of this study can then be applied in the study of other species of Darwinula, in order to explain variation in their AMS rosettes. The AMS pattern can then be used in species identification.

\section{THE MUSCLES AND MUSCLE-SCARS OF THE OSTRACODA}

The morphology of the valves and the soft parts, in particular of the appendages and genitalia, form the basis of the classification of the Ostracoda. Excepting exceptional circumstances, e.g. phosphatized ostracods with their appendages from the Cretaceous Santana Formation of Brazil (Bate, 1972) and from the Cambrian of Sweden (Müller, 1979, 1982, 1990), only the valves are available to the palaeontologist. Muscle-scars represent the attachment points on the valves of the muscles of the body. The many different muscles have a variety of functions including, in the case of the adductor muscles, the closing of the valves. The morphology of the AMS is used in the taxonomy of both Recent and fossil Ostracoda. Their number, shape, distribution and overall pattern provide the best direct correlation between the anatomy of the ostracod body and the morphology of the valves. The overall pattern of the AMS is used for distinguishing various suborders, superfamilies, families and subfamilies of ostracods. Finer details of the AMS often appear to distinguish genera, and in some cases even species (for example see van Morkhoven, 1962). Bate (1963) noted differences in the muscle-scars of the Cytheracea. He described four subtly different patterns based primarily upon variations in the development and shape of the frontal scar. These differences did not, however, serve to identify different genera, as several genera had the same pattern.

The body of an ostracod has many different sets of muscles. The arrangement of the muscle-scars in $D$. cicatricosa are shown in Fig. 3. Flexor and extensor muscles are present in all appendages, and in each podomere in order to enable independent movement. The basal podomere of each cephalic appendage is attached in the dorsal area of the valves: these attachment scars are known as the dorsal muscle-scar group. Dorsal muscle-scars were first described in Darwinula by Wakefield (1994). The basal podomeres of the mandibles are attached to the valves both dorsally, and slightly ventroanteriorly of the AMS. The adductor muscles extend from valve to valve, their attachment points forming the AMS. The adductor muscle bundle originates in the centre of the body where the striated muscle fibres connect to form a chitinous rod (Moore \& Pitrat, 1961), and pass, anterior to the mid-point of the body, laterally through the duplicature. The muscle fibres diverge as they approach the chitinous inner coating of the outer lamella (van Morkhoven, 1962). Ostracod muscles are attached to the valves by chitinous bosses which are inserted into the calcareous layer of the valve (Kesling, 1951). Attachment of the muscles to the bosses is through the interlacing of muscle myofibrils and boss tonofibrils (Smith, 1968). Some muscle-scars may be faintly subdivided into several parts by slight grooves known as scar-sutures (van Morkhoven, 1962). These scar-sutures may be formed by terminal bifurcations (Smith, 1968). These bifurcations may result, through the increase in the overall attachment area, in a greater strength of attachment.

\section{PREVIOUS RESEARCH ON THE AMS OF DARWINULA}

The distinctive, radially arranged AMS rosette of the Darwinulacea serves to differentiate the superfamily from almost all other ostracod superfamilies. Some myodocope ostracods (see Siveter \& Vannier, 1990, text-fig. 17) have similar AMS rosettes. Throughout this paper individual scars within the AMS rosette are referred to as segments, as in Fig. 3.

Gramm (1976) concluded that the number of segments within the AMS rosette of Darwinula had shown no evolutionary changes, such as increases or decreases in the 


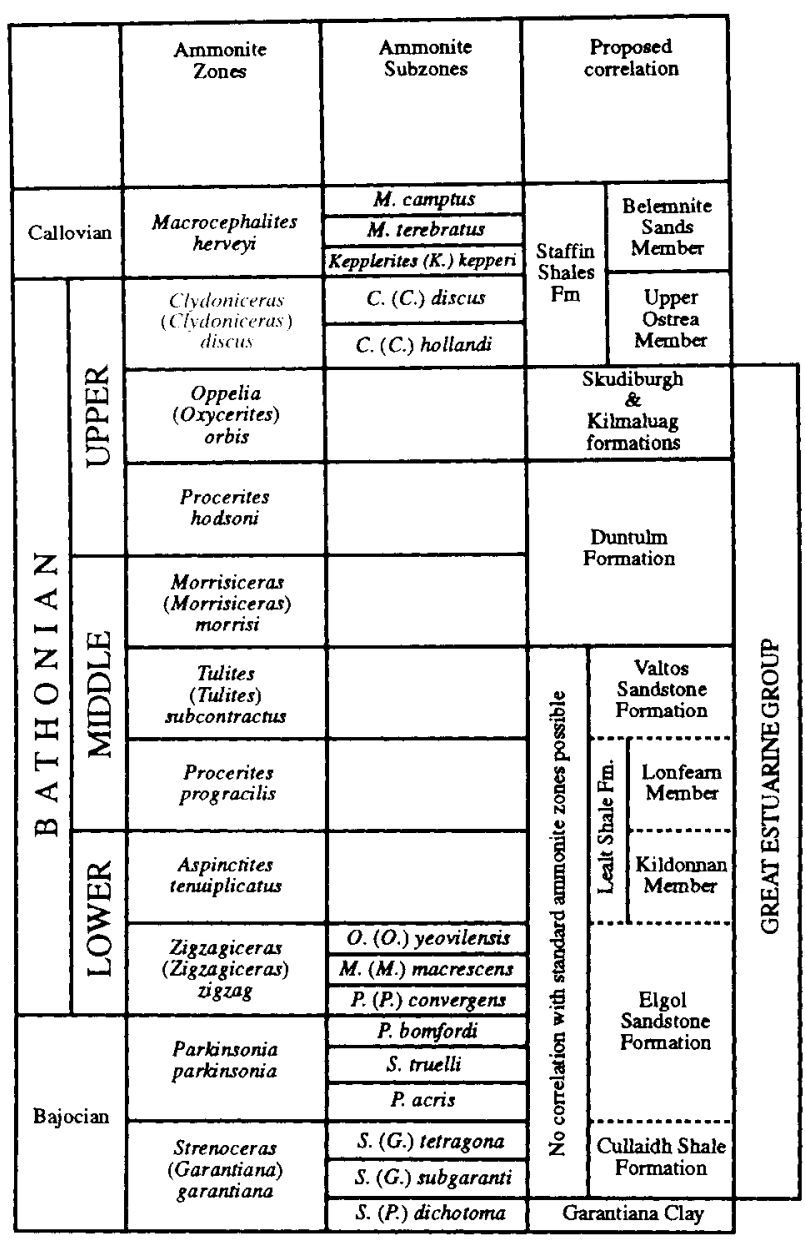

Fig. 1. Suggested correlation of the Great Estuarine Group with the standard ammonite zones (after Wakefield, 1994).

number of constituent segments within the rosette. Gramm's study was based on only a small number of species and is not discussed further.

Most research on the AMS of Darwinula has centred upon the type species, Darwinula stevensoni (Brady \& Robertson, 1870). Wagner (unpublished doctoral thesis, 1957, University of Paris) reported of $D$. stevensoni that the imprints of the muscle-scars were visible, they form a rosette. The number of imprints does not appear to be constant'. Wagner illustrated several different examples of AMS rosettes from D. stevensoni (Fig. 4a), three of the rosettes had 10 segments and one had 11. Triebel (1941) reported only nine segments, but he was the first to note a mandibular scar (Fig. 4b), a feature which has not subsequently been recorded. Sohn $(1976,1977,1987)$ figured 19 AMS rosettes from $D$. stevensoni, both from live collections taken in the field and from cultured specimens. He considered that the number (9-12), shape and disposition of individual segments within the AMS rosette showed great variation, and that such variation was independent of ontogeny. He agreed with Pinto \& Kotzian (1961) that the number of segments may also vary between

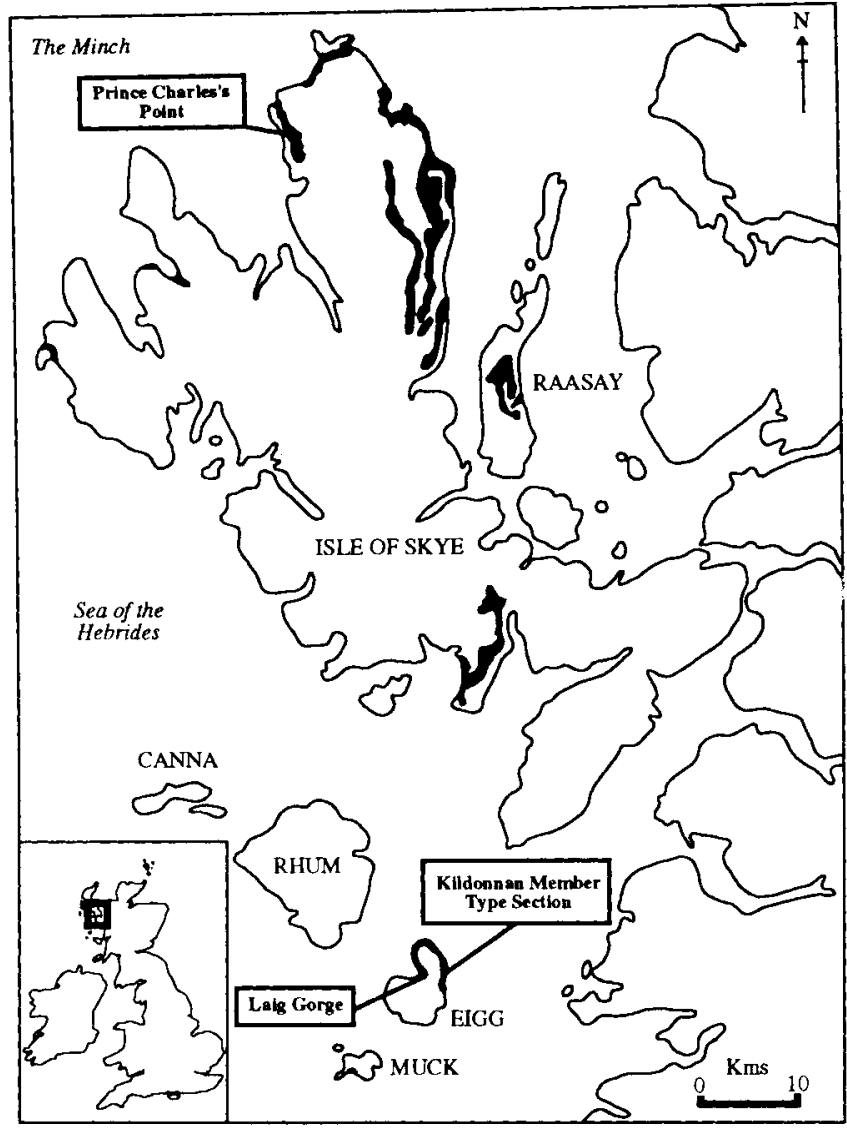

Fig. 2. Location of the Great Estuarine Group (shaded) and sections mentioned in the text.

the right and the left valves of the same carapace, and that the number of scars was not species specific.

\section{METHODOLOGY}

It was suggested that further development of scar-sutures would result in the subdivision of a scar and an increase in the number of segments within the muscle-scar field (van Morkhoven, 1962). Keij (1973) suggested that the division of individual scars within the basic AMS field of the bairdiidae resulted in the different patterns seen. He plotted out the AMS of several species of Harvanardia which had four, nine and 10 constituent scars, and showed how they could be derived from the basic four-scar pattern.

It was decided to see if the complete development of scar-sutures, resulting in segment division, could explain the variation seen in the AMS rosettes of Darwinula. The initial study was based upon a population of $D$. cicatricosa from the type level: Bed 7, Kilmaluag Formation, Great Estuarine Group, Prince Charles's Point, Trotternish, Skye (bed numbering from Andrews, 1985). This population consisted of carapaces of adults, A-1 and A-2 instars (Fig. 5), which had been infilled with diagenetic calcite. The specimens were mounted on glass slides using balsa cement (soluble in acetone), and the original valve material was broken away from the internal calcite mould, one valve at a time, using a steel needle. In breaking the original valves off their internal 


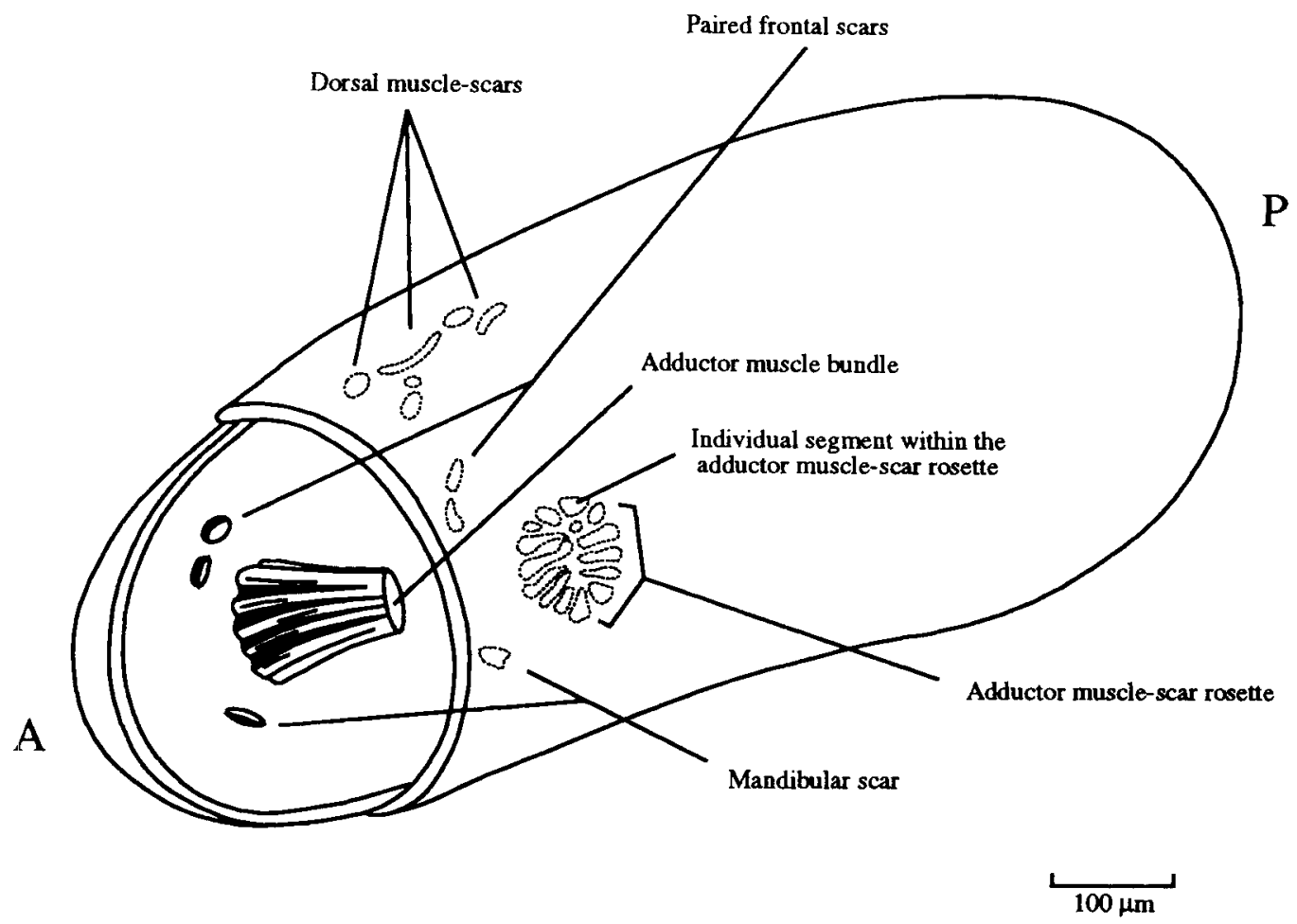

Fig. 3. Positions of muscle-scars in Darwinula cicatricosa. Anterior portion of left valve remove to show adductor muscle bundle.

calcite moulds the adductor, frontal, mandibular and dorsal muscle-scars became visible for both valves of each carapace. Some 34 individuals were prepared in this way, from which 64 AMS rosettes were photographed using an Hitachi S-520 Scanning Electron Microscope (SEM) on Ilford HPs 400 ASA black-and-white film. Accurate line drawings, counts and measurements were taken of the muscle-scars directly from the photographs.

After the initial tabulation of data, the AMS rosettes were arranged in order, based upon the number of segments within each rosette. The rosette with the least number of segments was chosen as a provisional standard for the species (Fig. 6a). Each segment was then labelled and its position relative to the other segments was noted. The other AMS rosettes were compared with this standard. Scarsutures were noted, and their positions compared with scars that were believed to have subdivided (Figs. 6a \& b). By careful comparison, it was possible to define idealized rosettes for each of the species on which could be marked the position of the scar-sutures, as well as guide lines i)
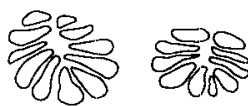

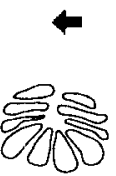

b)

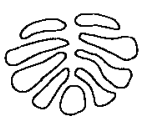

Fig. 4. Adductor muscle-scar rosette of Darwinula cicatricosa; from (a) Wagner (unpublished doctoral thesis 1957. University of Paris), (b) Triebel (1941). demarcating the arrangement of segments relative to one another. These idealized AMS rosettes can then be compared with one another, and used in species determinations.

Line drawings of AMS rosettes discussed in the text are numbered and shaded to aid in the identification of homologous segments within only that species. The similarity in shading between species is not intended to indicate homologies between species and should not be considered as such. All of the line drawings are produced so that they appear as if they were taken from an internal view of the valve. In some cases this has meant drawings being produced as mirror images of the original drawings which were from internal moulds. In so doing the confusion, which may have arisen, in having the anterior direction of drawings from the same valve facing in different directions, has been avoided.

It was decided to further check the hypothesis of segment division and increase by studying the AMS rosettes from other species of Darwinula. Unfortunately no other large populations of Darwinula were available from the Great Estuarine Group. However, it was possible to look at four AMS rosettes from Darwinula pulmo Wakefield, 1994, and to compare the AMS rosettes from Scottish and English specimens of Darwinula incurva Bate, 1967. SEM photographs and line drawings of $D$. stevensoni from Triebel (1941), Wagner (unpublished doctoral thesis, 1957, University of Paris) and Sohn $(1976,1977,1987)$ were also used in the comparative study.

Specimens numbered 10 or OS are housed in the collections of the Bitish Museum (Natural History), London. 


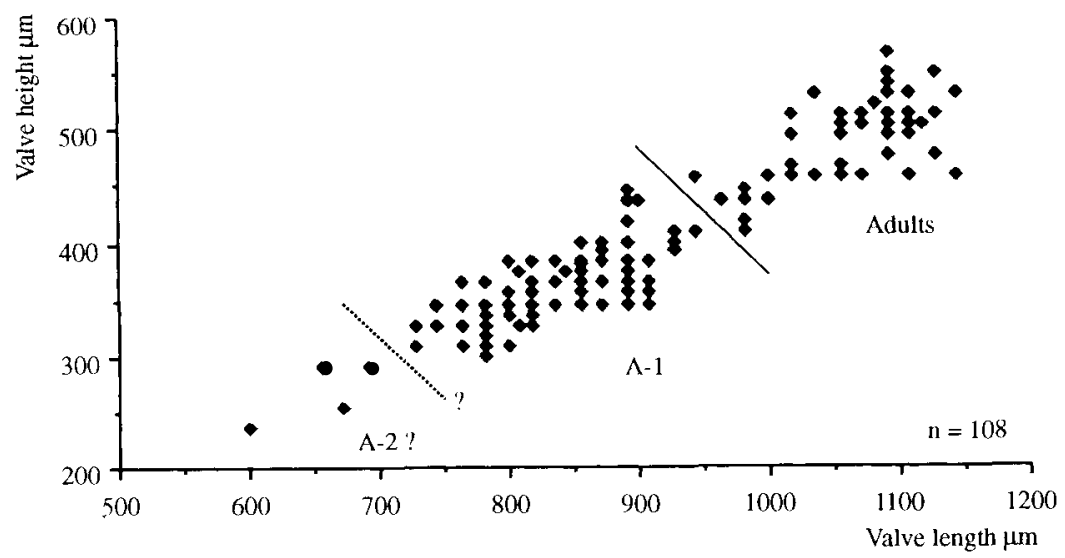

Fig. 5. Size dispersion of Darwinula cicatricosa from a single sample taken at the type level, Bed 7. Kilmaluag Formation, Prince Charles's point. Trotternish, Skye (from Wakefield, 1994).

Specimens from Sohn $(1976,1977,1987)$ are housed in the United States National Museum of Natural History (prefix USNM) or the Hancock Museum, Newcastle upon Tyne, England.

\section{THE AMS ROSETTE OF DARWINULA CICATRICOSA WAKEFIELD, 1994}

\section{Material}

One specimen of an A-2 instar, all other specimens (33) from A-1 instars and adults. All specimens were carapaces.

\section{Muscle-scar variation}

D. cicatricosa has a moderately variable AMS rosette with 9-15 segments (Fig. 7). The number of segments present in the AMS rosette varies not only between specimens but between valves of the same carapace. However, there does appear to be a general increase in the number of constituent segments within the rosette between A-1 instars and the adults (Fig. 8). The maximum diameter of the AMS rosette increases from a mean of $100 \mu \mathrm{m}$ in A-1 instars to $120 \mu \mathrm{m}$ in the adults. The diameter of the AMS rosette in each valve of a carapace is almost exactly the same (Fig. 9). Within an instar stage there does not appear to be a clear correlation between increase in diameter and increase in the number of segments within the AMS rosette. A mandibular scar was developed in all of the instar stages observed. In some instances (see Fig 7a [RV], b [RV], c [both valves], d [LV] \& e [both valves]) a median scar-suture was developed through the middle of the mandibular scar. In two instances (see Fig $7 \mathrm{a}[\mathrm{LV}] \& \mathrm{~g}[\mathrm{LV}])$ there were two mandibular scars present, the scar-suture having fully developed and thus divided the scar. There were usually two frontal scars developed, though in some specimens (Fig 7a ; both valves) the frontal scars had not developed. There was no observable ontogenetic difference between the development of the frontal and mandibular scars. This species is the only Darwinula to have been described with mandibular, frontal and dorsal scars (Wakefield, 1994).

\section{Development of scar-sutures}

Usually each AMS rosette is composed of 10 segments. However, in one instance there are only nine (Fig. 7c [LV]). The basal segment (number 5) in this specimen, however,

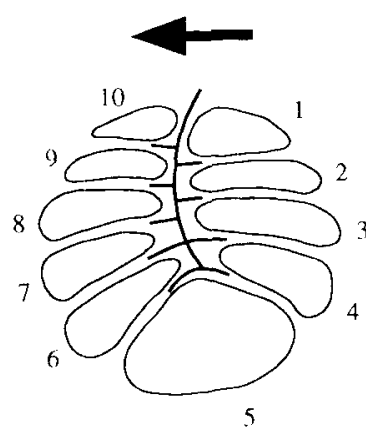

a)

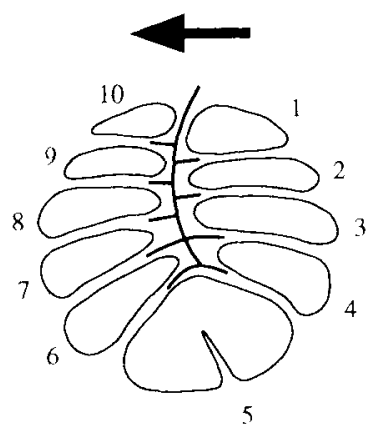

b)

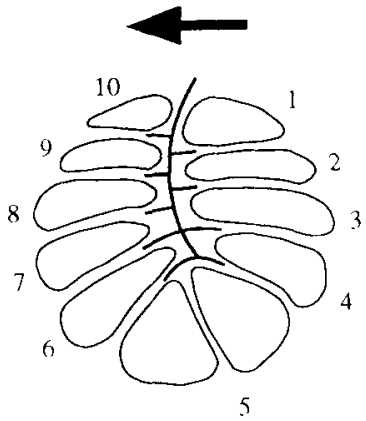

c)

Fig. 6. (a) AMS rosette with segments numbered and with lines indicating relative positions of one segment to another; 10 segments in all (b) AMS rosette with segments numbered, note scar suture in segment 5. (c) AMS rosette where scar sutllre in segment 5 has subdivided segment 5 into two, so that there are now $11^{\prime}$ segments in all. Numbering is based on (a) as is the arrangment of onc segment relative to another. 


$$
\text { RV }
$$

a)

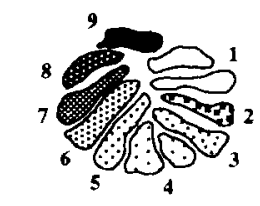

8

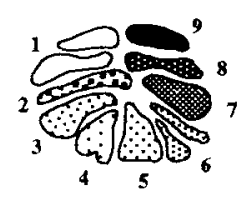

c)

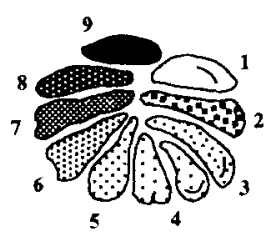

1

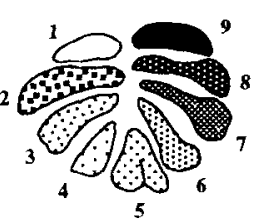

8

e)

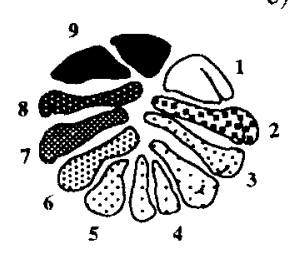

8

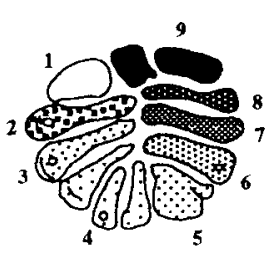

g)

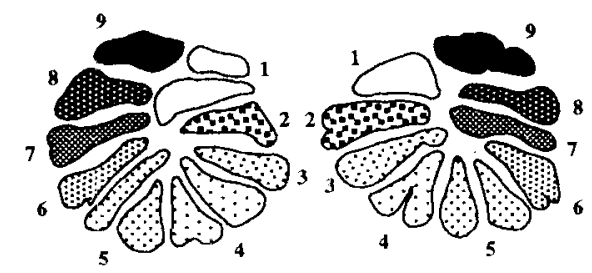

RV

b)

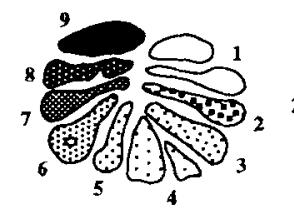

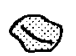

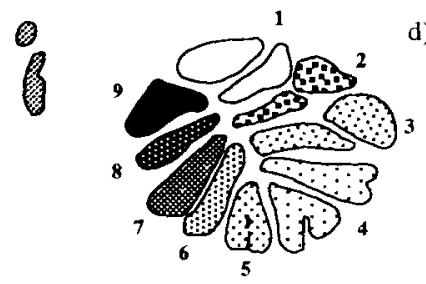

d)

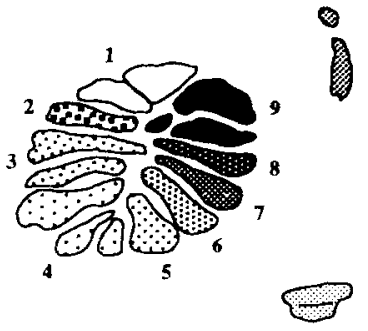

LV

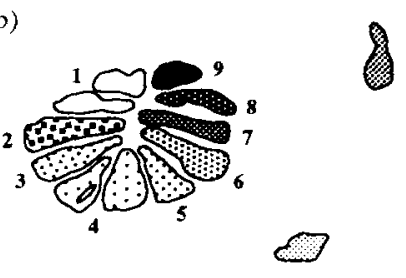

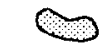
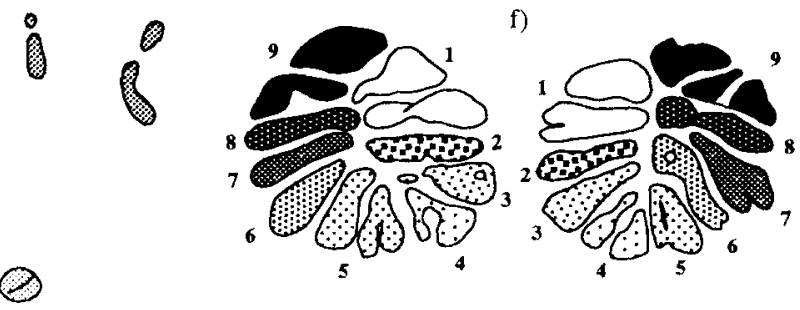

응

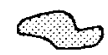

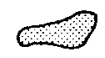

h)

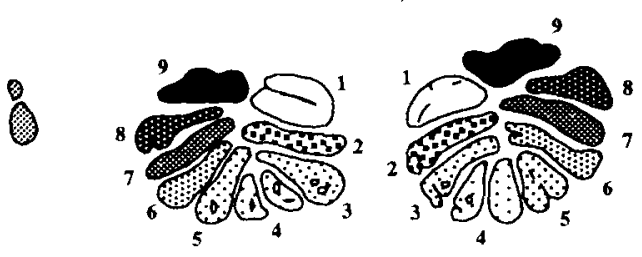

.

RV

LV

Fig. 7. Line drawings of the adductor muscle-scar rosettes, frontal and mandibular scars, from internal moukds (drawings reversed) of Darwinula cicatricosa (not to scale). (a) A-1 (specimen lost); (b) OS 13912, A-1: (c) A-1 (specimen lost), (d) OS 13913, adult: (e) OS 13914. A-1; (f) OS 13915, adult: (g) OS 13916, adult; (h) OS 13917. A-2. Al! specimens from the type level, Bed 7, Kilmaluag Formation, Prince (Charles's Point, Trotternish, Skye.

shows the partial development of a vertical median scar-suture: This feature is visible in several other specimens (Figs $7 \mathrm{~d}[\mathrm{RV}]$, e $[\mathrm{LV}] \& \mathrm{~h}[\mathrm{LV}]$ ), though in no cases does the segment actually divide into two. The first segment immediately to the posterior of the basal segment (number 4 ) is divided into at least two in all AMS rosettes with 10 or more segments. All the other segments within the AMS rosette remain in the same positions relative to one another 


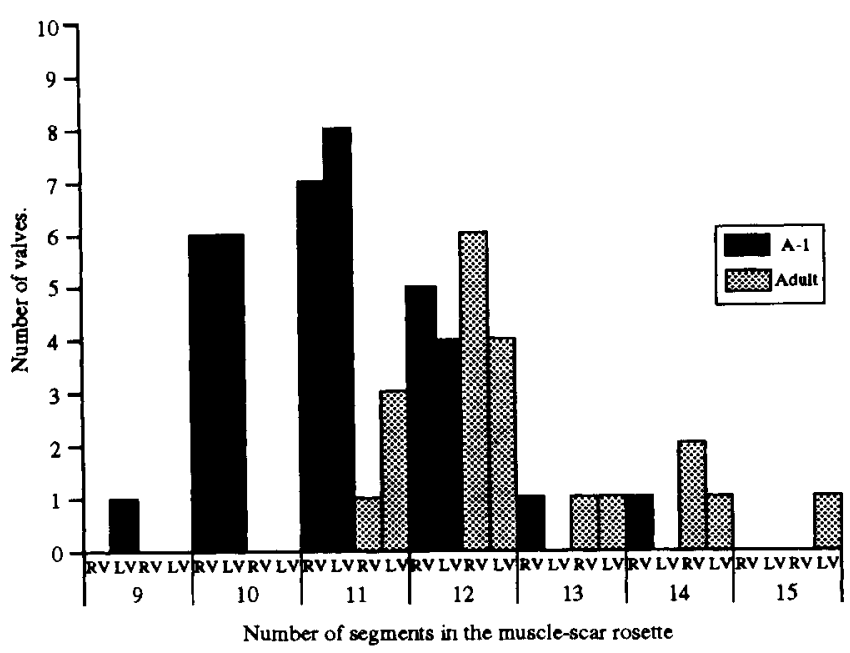

Fig. 8. Ontogenetic variation (increase) in number of segments in the adductor muscle-scar rosettc of left valves ( $\mathrm{LV}$ ) and right valves (RV), A-l instars to adults of Darwinula cicatricosa.

when this division takes place. This sub-basal segment is divided into three in several specimens (Fig. 7d [LV], e [both valves] \& $f[L V]$ ). In one specimen (Fig. 7d [RV]) this sub-basal segment is divided into two, with the basal of the two sub-segments clearly showing a vertical median scar-suture which all but divides it into two. The top segments on each side of the centre line (numbered $1 \& 9$ ))

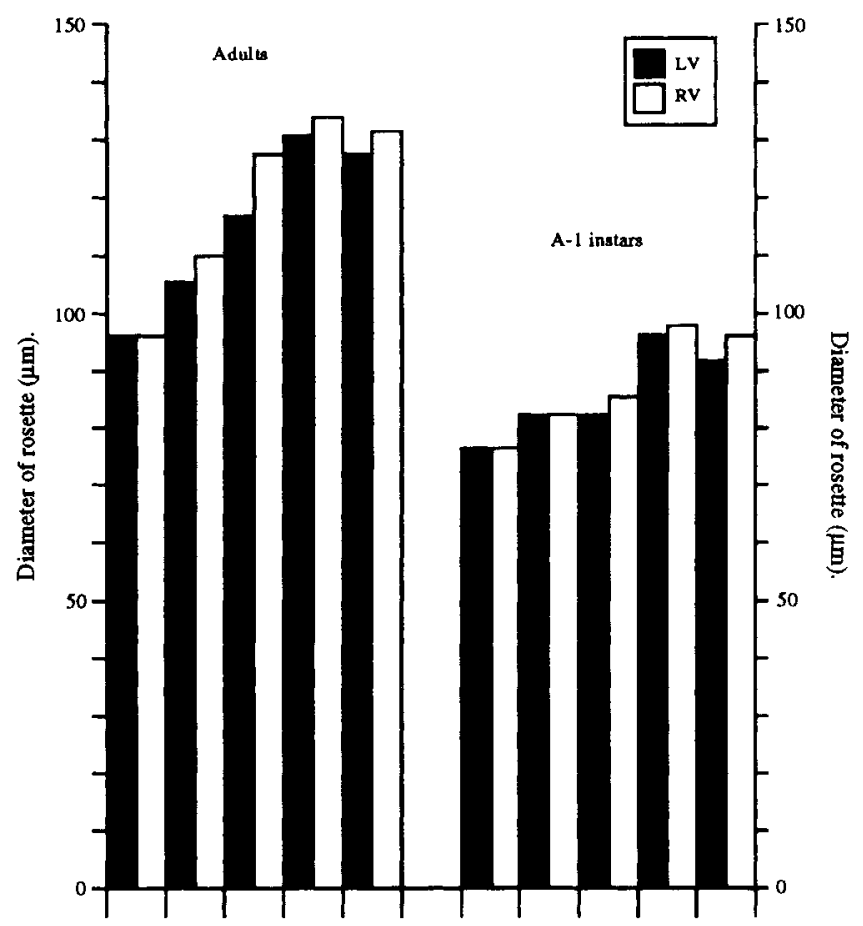

Fig. 9. Diameter of the adductor muscle-scar rosette of Darwinula cicatricosa showing the diameters of scars from the right and left valves of the same specimen (five specimens of adults and A-I instars). were occasionally subdivided, though no scar-sutures were noted in specimens with undivided upper segments e.g. Fig. $7 \mathrm{~b}$ [both valves] \& d [both valves]. Segment 9 divides horizontally into two, while segment 1 divides along oblique scar-sutures into two, though in a single specimen the outer sub-segment has further subdivided (Fig. 7f [LV]).

These standard divisions do not occur in any set order. However, the division of the sub-basal segment is, as previously stated, evident in all specimens with 10 or more segments. There are some apparently random subdivisions of the segments e.g. Fig $7 \mathrm{~d}$. However, these subdivisions do not alter the overall positions of the scars relative to one another.

\section{THE AMS OF DARWINULA PULMO WAKEFIELD, 1994}

\section{Material}

Four internal moulds of valves, three left valves and one right valve, no carapaces. All specimens from Bed 3, Kildonnan Member type section, Lealt Shale Formation, Great Estuarine Group, Eigg, of Harris \& Hudson (1980).

\section{Muscle-scar variation}

All of the AMS rosettes illustrated contain eleven segments (Fig. 10). There are slight differences in the shapes of individual segments, e.g. 3, 4, 6 \& 10. However, there is an overall similarity between the four specimens. Unfortunately there were not enough specimens to allow a similar study to that of $D$. cicatricosa.
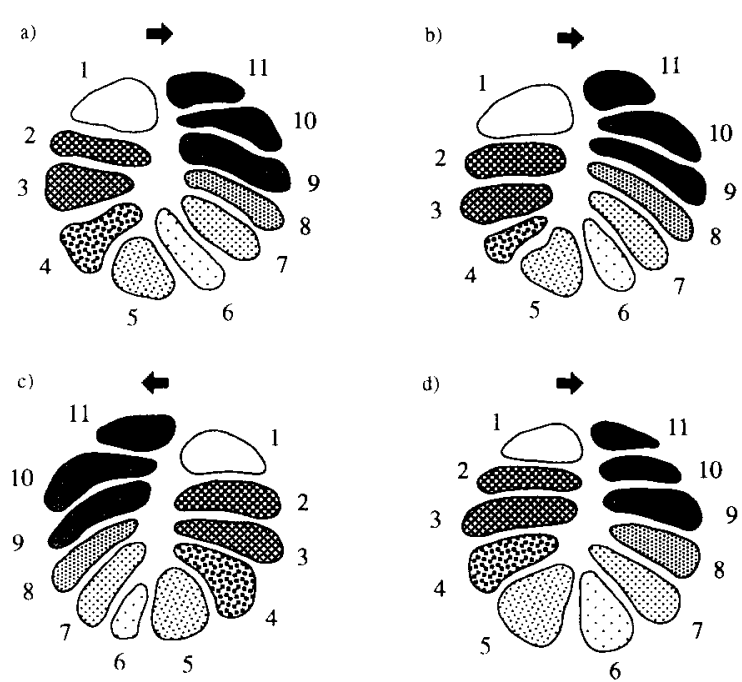

Fig. 10. Comparison of the muscle-scar rosettes of four specimens of Darwinula pulmo (not to scale). (a) OS 13899: internal mould of left valve: (b) OS 13900; internal mould of left valve: (c) internal mould of right valve (specimen lost), (d) OS 13901, internal mould of left valve. Specimens (c) \& (d) are from Bed 3g; (a) \& (b) are from Bed 6d; all from the Kildonnan Member type section, Lealt Shale Formation, Eigg. 


\section{THE AMS ROSETTE OF DARWINULA INCURVA BATE, 1967}

\section{Material}

D. incurva has been recorded from both England (Bate, 1965, 1967; Ware \& Whatley, 1980), the Inner Hebrides (Wakefield 1990, 1994), France (Rohr, unpublished doctoral thesis, 1976, University of Berlin) and China (Pang \& Whatley, 1990). The AMS rosettes were not illustrated in many of these papers. The AMS rosettes from Bates type material, numbers Io $\mathbf{2 2 7 4}$ and Io $\mathbf{2 2 6 2}$ were rephotographed on the SEM and line drawings made from the photographs. Specimens OS 13462 and OS 13459 of Wakefield (1990) and from two valve fragments from respectively, Bed 21, Duntulm Formation and Beds 1, 4 and 5, Kilmaluag Formation, G at Estuarine Group, Laig Gorge, Eigg, of Andrews (1985), were examined in a similar way (Fig. 11).

\section{Muscle-scar variation}

The variation in the AMS rosette of $D$. incurva was briefly discussed by Wakefield (1990). In most specimens the AMS rosette contains 11-13 segments, however, in one specimen (Fig. 11a) there are only 10 segments. Segment number 5 in this specimen has a weakly developed scar-suture which, in other specimens examined, has probably subdivided the basal segment into two sub-segments. Unfortunately this specimen was lost during transport to the British Museum (Natural History). Segment 5 may subdivide into more than two sub-segments (Fig. 11e). In one instance segments $6 \& 7$ have subdivided along obliquely orientated scar-sutures (Fig. 11f). These have not been observed in any other specimens. The arrangement of the segments relative to one
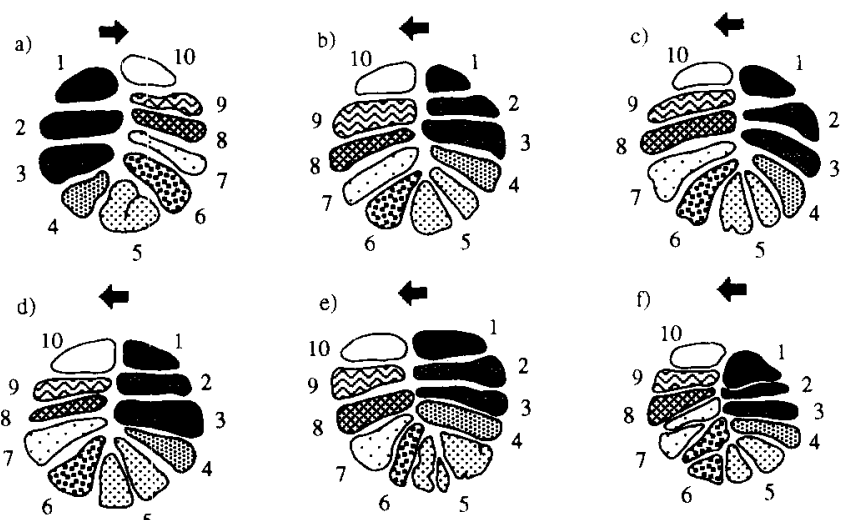

Fig. 11. Adductor muscle-scar rosettes of Darwinula incurva (not to scale). (a) A-1 internal mould of left valve (specimen lost), Bed 4, Kilmaluag Fim., Laig Gorge, Eigg; (b) A-1, internal mould of right valve (specimen lost), Bed 5, Kilmaluag Fm., Laig gorge, Eigg: (c) OS 13459; $A_{-}-2$, internal mould of right valve, Bed 1, Kilmaluag Fm., Laig Gorge, Eigg, (d) OS 13462; A-1, internal mould of right valve, Bed 21, Duntulm Fm., Laig Gorge, Eigg; (e) Io 2274; A-1, internal mould of right valve, Upper Estuarine Series at Thompsons Pit (Bate 1967); (f) Io 2262; adult right valve, Upper Estuarine Series at Kingscliffe (Bate, 1967). another within the AMS rosette is the same in all of the specimens studied.

\section{THE AMS ROSETTE OF DARWINULA STEVENSONI (BRADY \& ROBERTSON, 1870)}

\section{Material}

Line drawings of AMS rosettes from Triebel (1941) and Wagner (unpublished doctoral thesis, 1957, University of Paris) were used (Fig. 4) as well as line drawings (Fig. 12) made from the SEM photographs of Sohn (1976, 1977 and 1987). Some 22 different AMS rosettes were re-drawn for this study. The number, shape and distribution of the segments within each rosette were determined. As with the other species discussed above the segments are numbered and shaded.

\section{Muscle-scar variation}

A proposed standard with nine segments is given (Fig. 13d) This rosette was determined after study of all the specimens. Variations from this 'norm' can more easily be described. There is obviously variation in the number of segments developed between specimens $(8-12)$, though it is not possible to say if a component of ontogeny is present within this variation as was observed in $D$. cicatricosa. Sohn (1987), however, stated that there was no ontogenetic variation. There is also variation between valves of the same specimen, e.g., Figs $12 \mathrm{c} \& \mathrm{~d}$.

\section{Development of scar-sutures}

The positions of segment division are based upon the rosette standard (Fig. 13d). Dividing lines have been drawn between the segments in order to show their position relative to one another. These relative positions are useful when attempting to identify segments which have divided as the dividing segment still remains in the same position relative to the other segments.

The basal segment (number 5) is the site of the most regularly developed division. Segment 5 divides down its centre into two almost symmetrical sub-segments. This subdivided basal segment is present in almost all of the AMS rosettes which have 10 or more segments. The scar-suture which may develop to produce this subdivision is present in Fig. 12o.

Only one other segment appears to have divided in a large number of specimens, segment 9. It subdivides into two sub-segments along a horizontal median line. The two sub-segments are usually of a rounded triangular/arrowhead shape. From the published SEM photographs and line drawings it was not possible to find a specimen with a scar-suture developed in this segment before subdivision had taken place.

Figure $12 \mathrm{~h}$ clearly shows a scar-suture developed in segment 6 . This scar-suture, when fully developed, probably results in the two sub-segments seen in Fig. 12n.

Not all of the AMS rosettes studied could be compared favourably with the standard (Fig. 13d). The left valve of specimen USNM 151948 (Fig. 12b) is clearly different from the right valve (Fig. 12a) which has a subdivided segment 5 

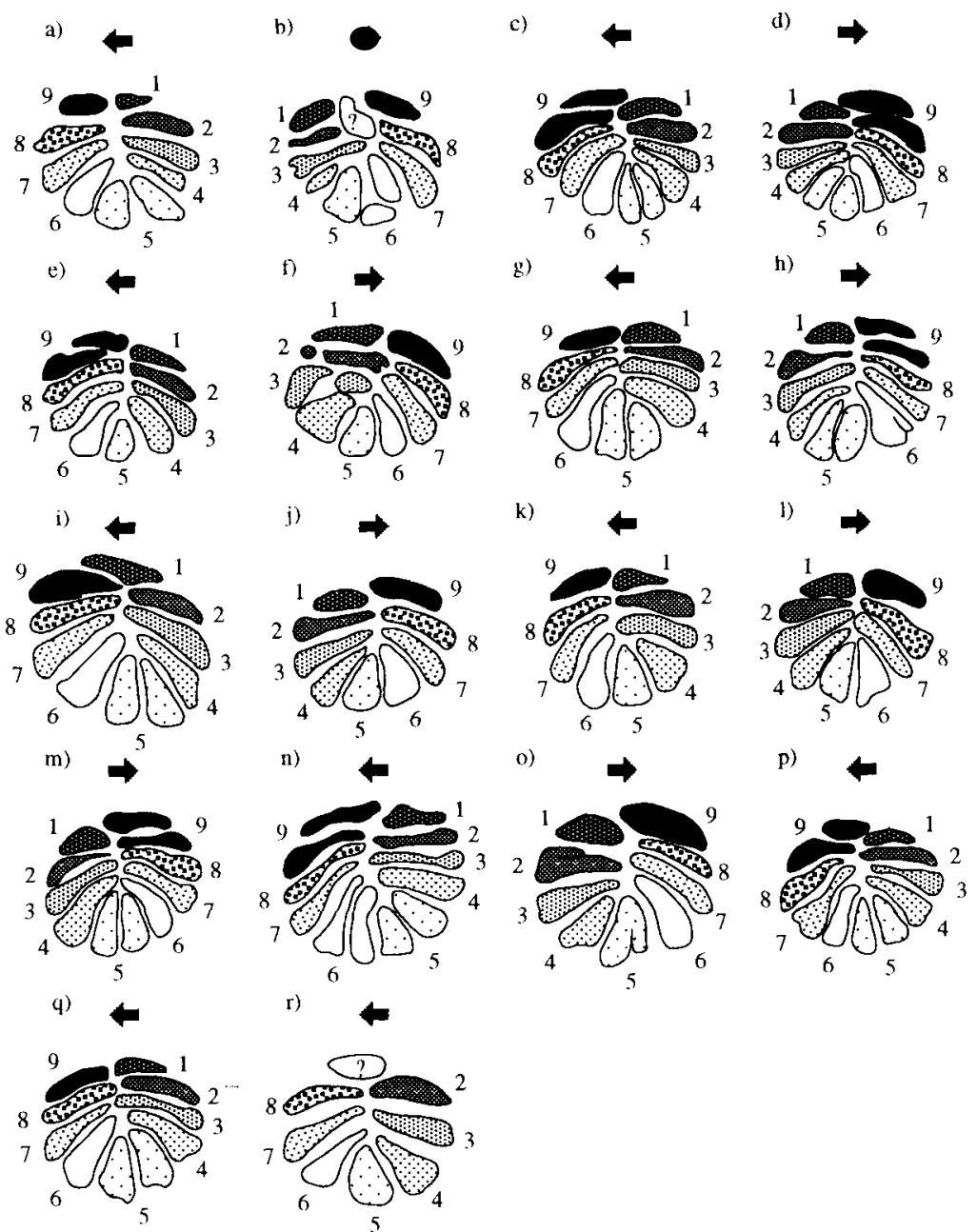

Fig. 12. Adductor muscle-scar rosettes of Darwinula stevensoni taken from SEM micrographs in Sohn (1976, 1977 \& 1987). Not to scale. (a) \& (b) USNM 151948, juvenile carapace from a laboratory culture; right valve, left valve. (c) \& (d) USNM 151949; juvenile carapace from a laboratory culture; right valve, left valve. (e) \& (f) USNM 151950; juvenile carapace from a laboratory culture; right valve, left valve. (g) \& (h) USNM IS1951; adult carapace from a laboratory culture; right valve, left valve. (i) Adult right valve from a laboratory culture, figured specimen subsequently lost. (j) USNM 151956; adult cararpace from Lake Tiberias, Israel; right valve, left valve. (k) USNM 151947; juvenile right valve from a laboratory culture. (l) Adult left valve from a laboratory culture, figured specimen subsequently lost. (m) Adult left valve from a laboratory culture, figured specimen subsequently lost. (n) USNM 151955; adult right valve from the Potomac River, Washington, USA. (o) USNM 171181; adult left valve from Yorkshire, England. (p) USNM 151952; adult right valve from a laboratory culture. (q) USNM 151953: adult right valve from a laboratory culture. (r) 1.56.06; paralectotype in Hancock Museum; adult right valve.

as described above. The AMS rosette from the left valve is completely different from that of any other AMS rosette of $D$. stevensoni figured. A possible interpretation of the rosette is given (Fig. 12b).

TAXONOMIC POTENTIAL OF THE AMS ROSETTE This paper proposes that the AMS rosettes of species of Darwinula are taxonomically useful in distinguishing individual species. Though the AMS rosette does vary within a species this variation is based upon a basic pattern particular to each species, which can be determined. These basic patterns from the species discussed above are clearly different (Fig. 13). Obviously detailed studies of each species and its AMS rosette are required before this proposal can be incontrovertibly confirmed.

\section{CONCLUSIONS}

(1) The AMS rosette of D. cicatricosa varies in the number of segments which comprise the rosette between individuals, between the two valves of the same individual and between instar stages (when comparing the average number of segments developed in each instar stage and the diameter of the rosette).

(2) Variation in the number of segments between individuals can also be demonstrated for $D$. pulmo, and $D$. incurva, and between individuals and valves of the same individual for $D$. stevensoni.

(3) The author agrees with Pinto \& Kotzian (1961) that the number of segments within the AMS rosette is not species specific.

(4) The variation in the AMS rosette within a species can 


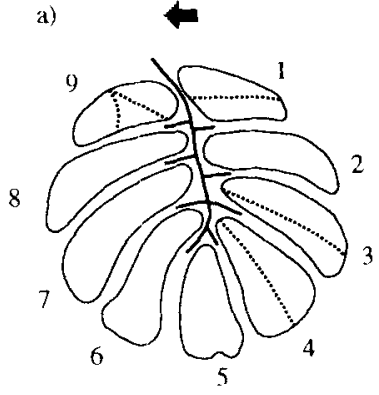

d)

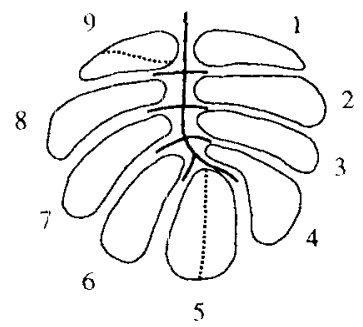

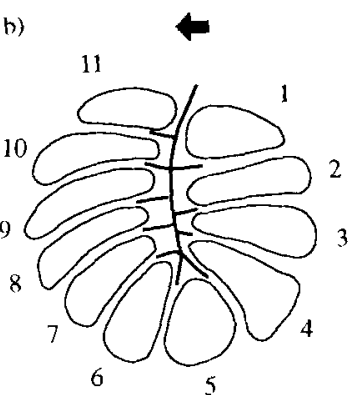

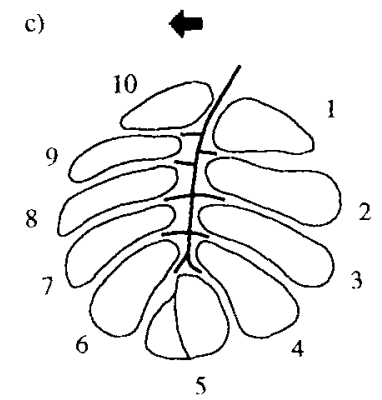

Scar sutures.

Show arrangement of segments.

Fig. 13. Idealized adductor muscle-siar rosettes for the right vaives of: (a) Darwinula cicatricosa, (b) Darwinula putmo, (c) Darwinula incurva, (d) Darwinula stevensoni.

be viewed as a series of subdivisions of specific segments within the rosette. The order in which these segments subdivide appears to be random both ontogenetically and phylogenetically. However, the basal scar in many of the species studied does appear to be the position of the most regularly developed scar-suture.

(5) Each species of Darwinula studied appears to have a distinctive AMS rosette. Use of the AMS rosette can assist in the diagnosis of species. The author therefore disagrees with Sohn (1987) who felt that the AMS rosette was of no diagnostic use. However, the use of any single AMS rosette to diagnose a species is considered, in the light of the variations noted, to be unwise.

\section{ACKNOWLEDGEMENTS}

This work was undertaken in the Department of Geology, University of Leicester, during the tenure of NERC/BP CASE Studentship GT4/88/GS/62. I would like to thank Prof. J. D. Hudson and Drs R. G. Clements, David J. Siveter and J. Athersuch for their supervision of my doctoral studies.

\section{Received January 1994 \\ Accepted October 1994}

\section{REFERENCES}

Andrews, J. E. 1985. The sedimentary facies of a late Bathonian regressive episode: the Kilmaluag and Skudiburgh formations of the Great Estuarine Group. Inner Hcbrides. Scotland. Joumal of the Geological Society of London, 142: 1119-1137.

Bate, R. H. 1963. Middle Jurassic ostracods from North Lincolnshire. Bulletin of the British Museum (Natural History), Geology, 8(4): 173-219.

Bate, R. H. 1965. Freshwater ostracods from the Bathonian of Oxfordshire. Palaeontology, 8(4): 749-759.
Bate, R. H. 1967. The Bathonian Upper Estuarine Series of eastern England, Part 1. Ostracoda. Bulletin of the British Museum (Natural History), Geology, 14(2): 21-66.

Bate, R. H. 1972. Phosphatised ostracods with appendages from the Lower Cretaceous of Brazil. Palaeontology, 15(3): 379-393.

Gramm, M. N. 1976. On two tendencies in the evolution of ostracod adductor muscle scar. Abhandlungen und Verhandlungen Naturwissenschaftliches Vereins, Hamburg (NF), 20(Suppl.): 287294.

Harris, J. P. \& Hudson, J. D. 1980. Lithostratigraphy of the Great Estuarine Group (Middle Jurassic), Inner Hebrides. Scottish Journal of Geology, 16: 231-250.

Keij, A. J. 1973. Recent west African Harvanardia species (Ostracoda). Proceedings of the Koninklike Nederlandse Akadamie van Wetenschappen, Series B, 76(4): 316-328.

Kesling, R. V. 1951. The morphology of ostracod moult stages. Illinois University Biological Monographs, 21(1-3): 1-26.

Moore, R. C. \& Pitrat. C. W. 1961. Treatise on Invertebrate Palaeontology, Part Q, Arthropoda, 3. University of Kansas Press.

Müller, K. J. 1979. Phosphatocopine ostracodes with preserved appendages from the Upper Cambrian of Sweden. Lethaia, 12: $1-27$.

Müller, K. J. 1982. Hessandona unisulcata sp. nov. with phosphatised appendages from Upper Cambrian 'Orsten' of Sweden. In Bate, R. H., Robinson, J. E. \& Sheppard, L. M. (Eds), Fossil and Recent Ostracods. Ellis Horwood Ltd., Chichester, 276-304.

Müller, K. J. 1990. Upper Cambrian 'Orsten'. In Briggs, D. E. G. \& Crowther, P. R. (Eds), Palaeobiology, a Synthesis. Blackwell Scientific Publications, Oxford, 274-277.

Pang Qiqing. \& Whatley, R. C. 1990. The biostratigraphical sequence of Mesozoic non-marine ostracod assemblages in northern China. In Whatley, R. C. \& Maybury, C. (Eds), Ostracoda and Global Events. Chapman \& Hall, London, 239-250.

Pinto, I. D. \& Kotzian, S. C. B. 1961. New ostracodes of the family Darwinulidae and the variation in their muscle scars. Universidade do Rio Grande do Sul, Instituto de Ciências Naturais, Bolletin, 11: 5-64.

Siveter, D. J. \& Vannier, J. M. C. 1990. The Silurian myodocope 
ostracode Entomozoe from the Pentland Hills, Scotland: its taxonomic, ecological and phylogenetic significance and the affinity of the bolbozoid myodocopes. Transactions of the Edinburgh Geological Society, 81: 45-67.

Smith, R.N. 1968. Frontal muscle scars of Trachyleberidinae and Hemicytherinae (Ostracoda). Science, 161: 808-809.

Sohn, I. G. 1976. Antiquity of the adductor muscle attachment scar in Darwinula Brady \& Robertson, 1855. Abhandlungen und Verhandlungen Naturwissenschaftliches Vereins, Hamburg (NF), 18/19 (Suppl.): 305-308.

Sohn, I. G. 1977. Muscle scars of late Paleozoic freshwater ostracodes from west Virginia. Journal of Research of the United States of America Geological Survey, 5(1): 135-141.

Sohn, I. G. 1987. The ubiquitous ostracode Darwinula stevensoni (Brady \& Robertson, 1870), re-description of the species and lectotype designation. Micropalaeontology, 33(2): 150-163.

Triebel, R. 1941. Zur morphology und oekologie der fossilen ostracoden. Senckenbergiana Lethaea, 23(4/6): 294-400.

Van Morkhoven, F. P. C. M. 1962. Post-Palaeozoic Ostracoda. Their Morphology, taxonomy and economic use. Volume 1. Elsevier, London.

Ware, M. \& Whatley, R. C. 1980 . New genera and species of Ostracoda from the Bathonian of Oxfordshire, England. Revista Espanola de Micropaleontologia, 12(2): 199-230.

Wakefield. M. 1. 1990. On Darwinula incurva Bate. A Stereo-Atlas Ostracod of Shells, 17(8): 41-44.

Wakefield, M. I. 1994. Middle Jurassic (Bathonian) Ostracoda (Crustacea) from the Inner Hebrides, Scotland. Monograph of the Palaeontographical Society, London, 1-90 (Publ. No. 593, part of Vol. 148 for 1994). 